\title{
Preliminary Assessment of Environmental Performance of Ice Formwork Production Method for Irregular Architectural Elements of Concrete
}

\author{
Vasily Sitnikov* [0000-0003-1812-5525], Patrick Rogers ${ }^{\text {a }}$ [0000-0001-7820-4052] \\ * KTH School of Architecture, Stockholm, Sweden. vasily.sitnikov@arch.kth.se \\ ${ }^{a}$ RISE Research Institutes of Sweden
}

\begin{abstract}
The present article communicates knowledge in sustainability of a method of digital fabrication in precast concrete production. The method, known as Ice Formwork, serves in production of ultrathin lightweight architectural elements - a novel design typology that has emerged with the development of High-Performance Fibre-Reinforced Concrete (HPFRC). This class of prefabricated concrete structures is expected to reduce cement consumption, adopt digital fabrication processes, and increase design flexibility. In practice however, this production employs suboptimal methods of mould-making, using petrochemical or engineered wood products for single-use moulds. Thus, the excessive amount of non-recyclable waste raises the question of qualities of the advanced digital precast concrete production.
\end{abstract}

The current work builds on the research and development of a novel production method Ice Formwork facilitated through single-use moulds made of artificially frozen water. Previously published work on the subject has covered topics such as cement hydration at subfreezing temperature (Sitnikov and Sitnikov 2018), subtractive digital processing of ice (Sitnikov 2019), and a case of practical application illustrated with the production of a prototype of a lightweight façade rain screen (Sitnikov et al. 2019).

Yet, since artificial refrigeration and processing of large amounts of water is essential for Ice Formwork production, the environmental performance of this method requires a thorough examination. Thus, the current piece of work attempts to address two major issues, namely:

1. Energy consumption of industrial refrigeration in production of Ice Formwork.

2. Changes in water mineral content after a cycle of Ice Formwork concrete production.

For both topics, the research work required development of an original experimental methodology. This aspect has been given great attention and required development of new technical solutions on many levels. Further research and development is needed to come to a comprehensive environmental assessment, and the results of the current study merely provide a preparatory overview that can help to orient and properly set the objectives for the following research stages.

Keywords: Ice Formwork, High-Performance Concrete, Digital Fabrication, Refrigeration, Embodied Energy, Grey energy, Carbon Footprint. 


\section{Introduction}

Concrete is said to be humanity's single most used material by mass, with annual application exceeding $60 \mathrm{Gt}$ worldwide (Flatt, Roussel, and Cheeseman 2012). Among its main raw materials, production of cement clinker is commonly associated with causing a high impact on the environment, with annual carbon dioxide production-related emissions amounting to $2.2 \mathrm{Gt}$. This is equivalent to six percent of global $\mathrm{CO}_{2}$ emissions. Thus, for several decades, a lot of attention has been dedicated to the technologies aimed at the reduction of cement clinker consumption, while meeting the growing need for concrete in the construction industry.

One of the promising strategies of reducing cement clinker consumption lies in the combination of computational tools of design and material processing applied to high-performance fibre reinforced concrete (López López et al. 2014). This strategy allows significant reduction of the mass of concrete structures, leading to lower consumption of cement clinker per structural member. In practice, this method has been used in a number of projects where these design topologies were used for building envelopes, the brightest examples being The Broad (Diller Scofidio + Renfro 2015), Foundation Louis Vuitton (Gehry Partners 2014), and Sejong M-Bridge (Morphosis 2020).

The physical properties of HPFRC allow it to reduce the element's overall thickness to a mere 20-40 $\mathrm{mm}$, making this structure extremely light, reaching $100 \mathrm{~kg} / \mathrm{m}^{2}$ (Gannon 2018; Schipper et al. 2014). However, designs of façades often require geometrical customization, therefore geometry and dimensions of elements have to change from one element to another. Most commonly, the industry meets the production requirements of challenging projects with the digital fabrication workflow based on robotic processing of expanded polystyrene (EPS), which provides a relatively simple, fast and automated process of mould production. Despite all the convenience, this production model has a number of drawbacks. Firstly, it inevitably generates non-recyclable polystyrene waste. EPS debris ends up being incinerated, releasing carbon dioxide into the atmosphere, or being dumped in landfills, polluting the land and/or the ocean. Considering that the amount of solid plastic waste in landfills has increased by an order of magnitude in the period from 1960 to 2000 (Jambeck et al. 2015), increasing the plastic consumption of the building industry today means increasing the environmental impact negatively.

However, a less recognized waste factor that occurs in the EPS-based production flow is the waste of energy embodied in this material. This is the energy invested in the foam block during the stages of crude oil extraction, industrial processing, and transportation of polystyrene to the place of consumption (Fig. 1). The embodied energy of polystyrene is very high, approximately $88 \mathrm{MJ} / \mathrm{kg}$, compared to the embodied energy of concrete, which is a mere $0.8 \mathrm{MJ} / \mathrm{kg}$ (Hammond and Jones 2011). However, since a custom designed concrete product requires a single use mould, the use of EPS inflates the embodied energy of concrete end-product from $0.8 \mathrm{MJ} / \mathrm{kg}$ up to approx. $20 \mathrm{MJ} / \mathrm{kg}$ (although, depending on the design of the formwork, this value can vary).

\subsection{Introduction of the ice-based method of concrete prefabrication - Ice formwork}

In an attempt to counteract the disadvantages of conventional mould-making outlined above, the research in digital solutions of concrete prefabrication has been taking place for a couple of decades, leading to a very promising technology of concrete 3D-printing. On one hand, the technology aspires to provide a flexible fabrication method for various concrete classes including HPFRC. On the other hand, concrete additive fabrication lacks dimensional accuracy and causes problems in structural performance due to the very nature of concrete deposition in discrete layers during printing. These inherent qualities hold the technology back from industrial implementation and limit the range of its possible use. 
The concept of Ice Formwork attempts to maintain the qualities of precast concrete while changing the mould material from the petrochemical products to artificially frozen water. The feasibility, functionality, and practical benefits of Ice Formwork have been advocated in previously published work, covering the topics of cement hydration at subfreezing temperatures (V. Sitnikov and Sitnikov 2018b), subtractive digital processing of ice (V. Sitnikov 2019), and practical application of the method in a design case of a lightweight rain screen façade element (V. Sitnikov et al. 2019).

Although the use of ice as the moulding material has gained very little attention, conceptually this material choice has significant rationales. To begin with, tap water that can be used for the production of ice has an extremely low embodied energy - about $0.01 \mathrm{MJ} / \mathrm{kg}$, and the smallest carbon footprint at $0.000275 \mathrm{kgCO}_{2} \mathrm{eq} / \mathrm{kg}$ water (Ecoinvent 2020), though these values vary depending on region. Although energy is also required to freeze tap water, it is a minor energy investment in comparison to the industrial production of expanded polystyrene (Fig. 1). Finally, the fact that water can be continuously re-frozen within the concrete production facility suggests that this material system can be very efficient and economical. This list of arguments constitutes the main line of advocacy in favour of the development of Ice Formwork production method.
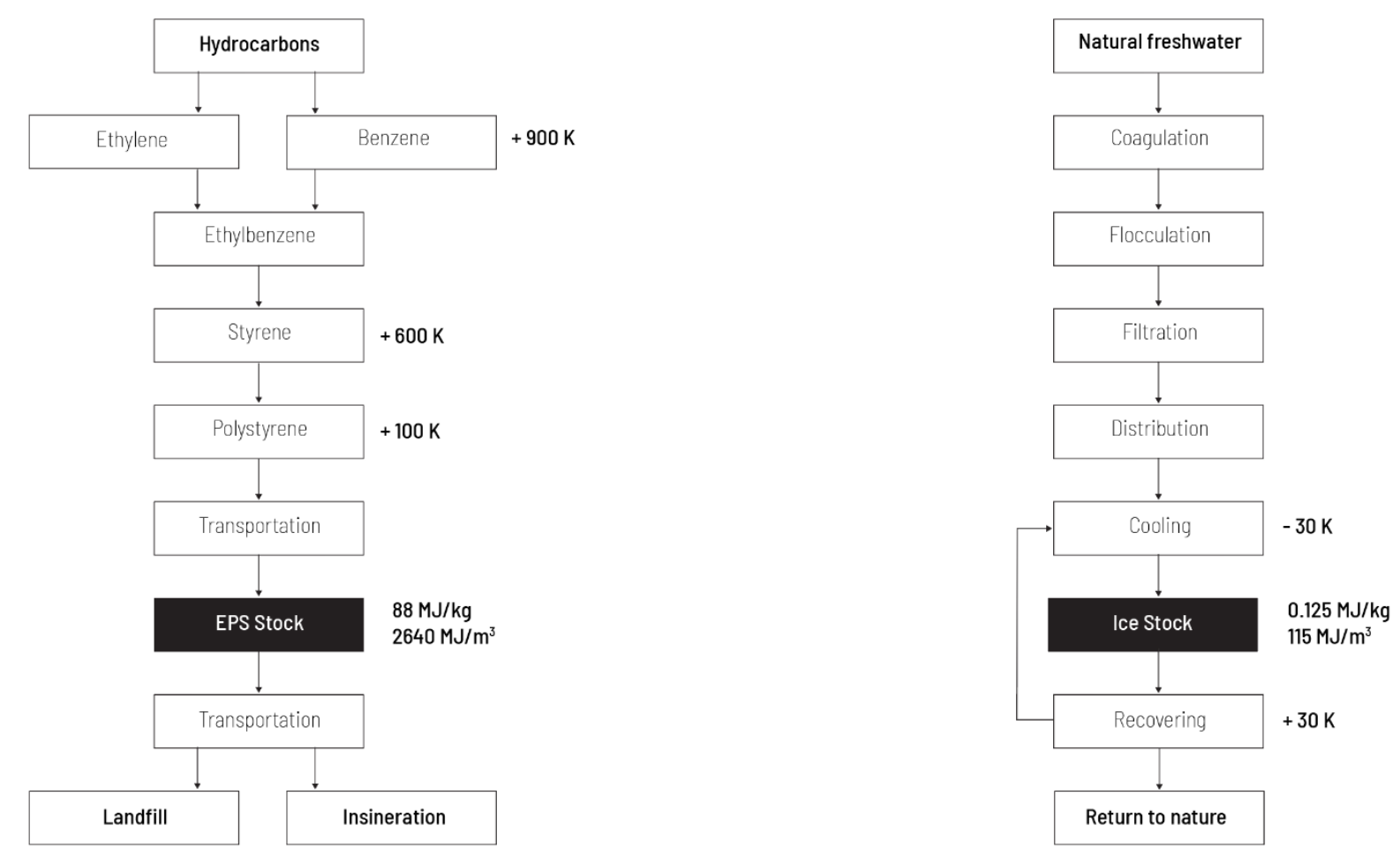

Figure 1: Comparison of the life cycle of expanded polystyrene and industrially frozen water. Embodied energy of EPS stock material is borrowed from Hammond and Johns 2012; the embodied energy of water is a simple calculation based on the gram calorie unit. 


\section{The study objective}

In order to support the abovementioned arguments with factual data, the current research attempts to examine two of the main environmental issues raised by the concept of Ice Formwork. Precisely, these issues can be formulated in two questions:

1) What would be the energy consumption of refrigerated production of concrete elements?

2) How does the chemical content of water change after a production cycle?

Due to the early stage of development, the questions pose significant challenges. Both topics require deepening in the specific scientific fields of energy engineering and water chemistry. Therefore, the current article attempts to address these questions with quantitative empirical data collected during the experimental work. Though this data is limited to a rather small scale of material processing, it is still sufficient to address the environmental qualities of the production principle.

\section{Experimental Data Collection}

\subsection{Experimental Rig}

To evaluate the energy consumption of a concrete prefabrication process based on an artificially refrigerated environment, a prototype of a production facility was set up in Stockholm, Sweden for a period from April through December 2019. The testing facility was based on a standard 20 -foot refrigerated shipping container set to a constant temperature of $-10^{\circ} \mathrm{C}$. During this test period, the 45 cubic meters of refrigerated space accommodated the production of ice stock material, subtractive ice processing on a three-axis CNC mill, including the storage, mixing and moulding of concrete on the ice formwork (Fig. 2). The setup was used as a prototype of a production site and allowed empirically assessing the aspects of energy consumption, functioning of various equipment at subfreezing temperatures, time requirements, and other nuances associated with the Ice Formwork production method.
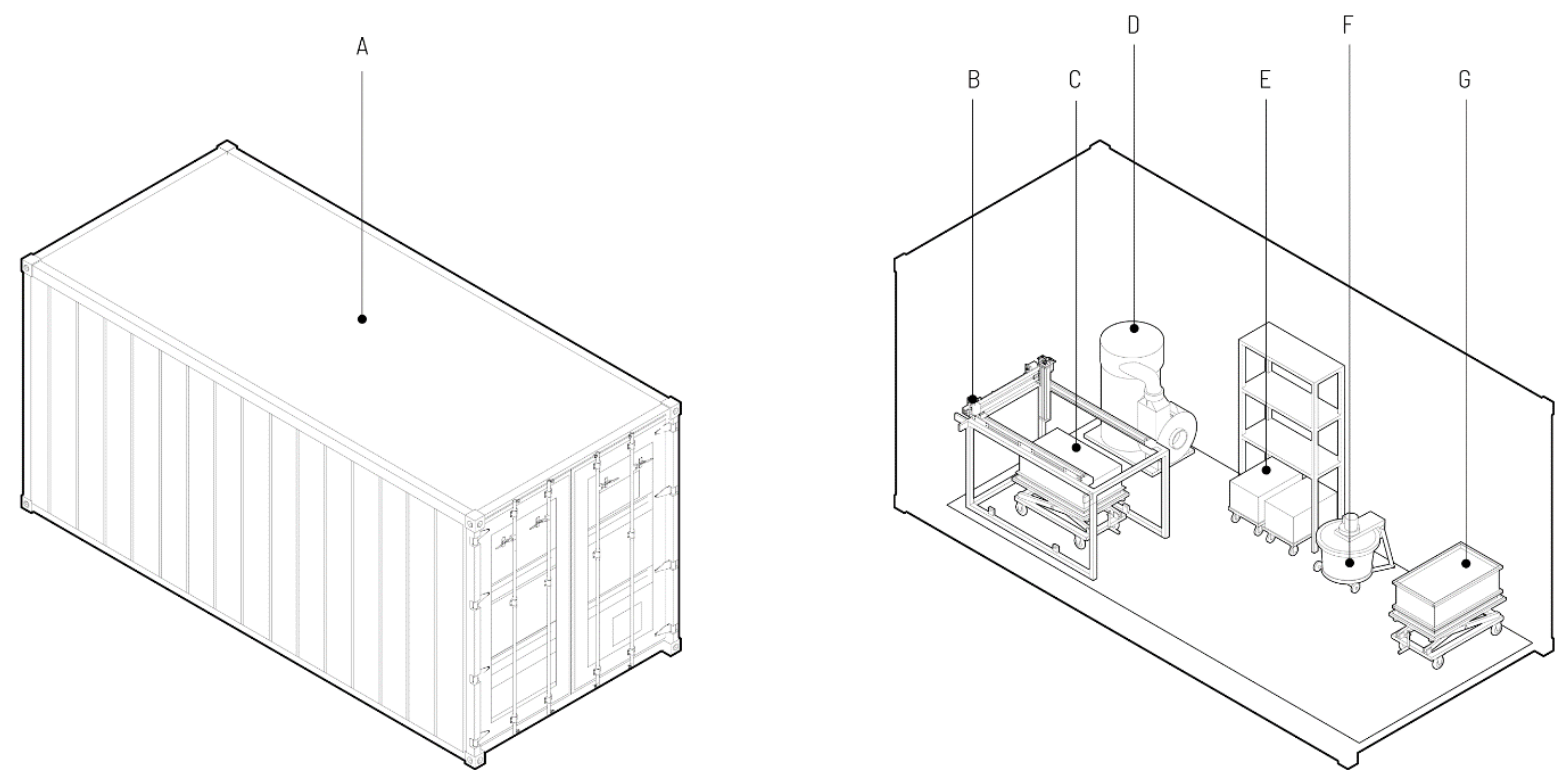

Figure 2 - Scheme of the fabrication setup based on a 20' industrial refrigerator. (A - ISO 20' industrial refrigerated container; B - CNC mill; C - ice stock; D - dust extractor; E - raw materials; F - concrete mixer; G - ice stock production). 
The current subchapter provides an analysis of energy data collected during the experimental period. The setup was used for production of two middle-scale prototypes - Prototype A (inventory code 190703C-HII) and Prototype B (inventory code 190912C-FCII). Their designs play an important role in the energy evaluation and thus are described below.

\section{Design of the Prototypes Used to Obtain Energy Consumption Data}

Prototype A (Fig. 3 \& Fig. 5) is a thin-wall hollow core façade element with dimensions $900 * 600 * 90$ $\mathrm{mm}$, mass of $53 \mathrm{~kg}$, and wall thickness of approx. $10 \mathrm{~mm}$. The formwork was produced in combination with CNC milling and manual assembling. The mould consisted of ten CNC milled ice parts, which were placed in a laminated plywood box and fused together into one continuous ice structure by addition of a thin layer of water on the bottom. The distances between the ice parts were controlled using CNC milled ice-spacers of $10 \mathrm{~mm}$. Since each of the ten parts had an overhang on the edge, they formed undercut volumes in concrete - a challenging topology for conventional production methods of precast concrete.

Prototype B (Fig. 4 \& Fig. 5) is a lightweight rain screen façade element produced with a mould assembly of two parts - a mould and a counter-mould. The dimensions of the end-product are $760 * 400 * 150 \mathrm{~mm}$ with a mass of approx. $28 \mathrm{~kg}$. The thickness of concrete is $20 \mathrm{~mm}$ throughout the piece. The design and fabrication have been thoroughly described in a previously published article (Sitnikov et al. 2019).

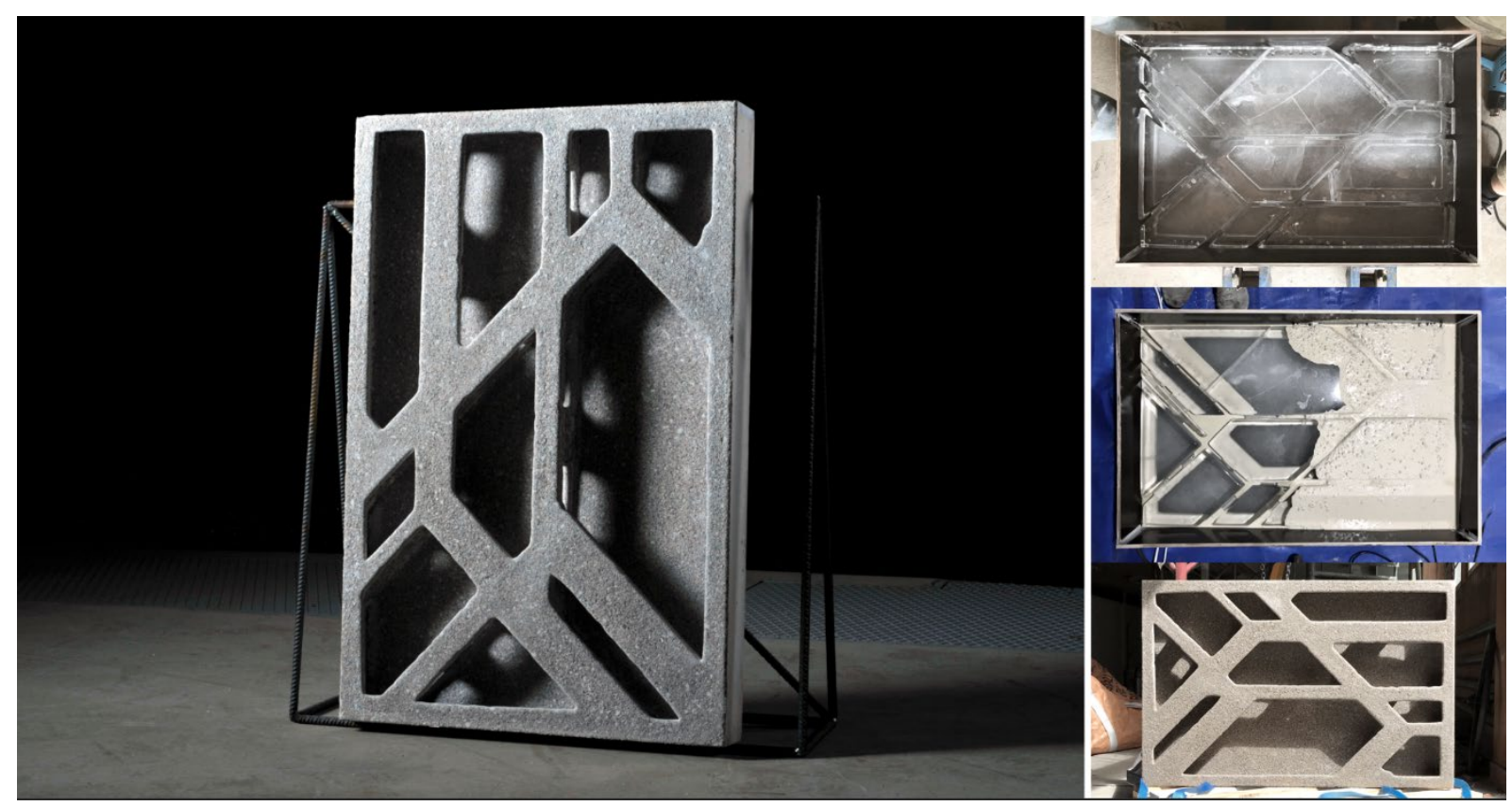

Figure 3 - Prototype A - hollow core element; and production stages: the complete mould assembly, concrete pouring, and the cast after demoulding. 


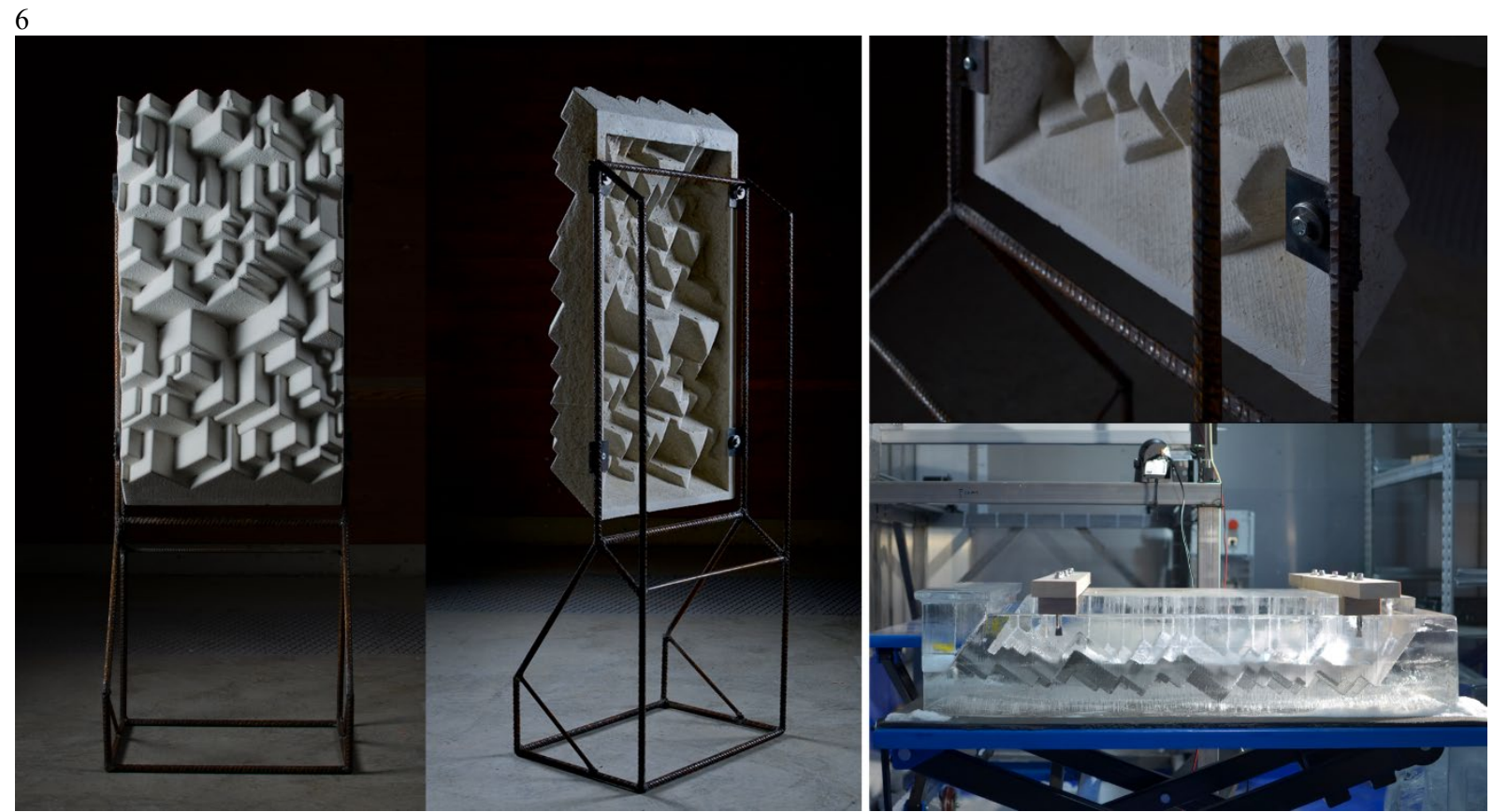

Figure 4 - Prototype B - light-weight rain-screen façade front and backside, anchoring detail and the ice mould assembly.

As can be seen from Figures 3 and 4, the design geometry and the mould assemblies are very different, leading to a different energy performance in relation to mass of concrete end-products. The predominant role in production efficiency is played by the ratio between the volume of the mould stock material and the mass of the concrete end-product: the higher the volume of mould stock material for production of a concrete element, the greater the amount of embodied energy for the end product. Therefore, the different prototype designs allowed a range of the energy performances of the Ice Formwork production to be mapped. 
Prototype A

$\begin{gathered}\text { Mould Stock Material } \\ \text { Volume }=0,048 \mathrm{~m}^{3}\end{gathered}$
CNC Mould Parts

Prototype B

$\begin{array}{ccc}\begin{array}{c}\text { Mould Stock Material } \\ \text { Volume }=0,102 \mathrm{~m}^{3}\end{array} & \text { CNC Mould Parts } & \text { Concrete product } \\ \text { Volume }=0,059 \mathrm{~m}^{3} & \text { Mould Assembly } & \text { Volume }=0,012 \mathrm{~m}^{3}\end{array}$

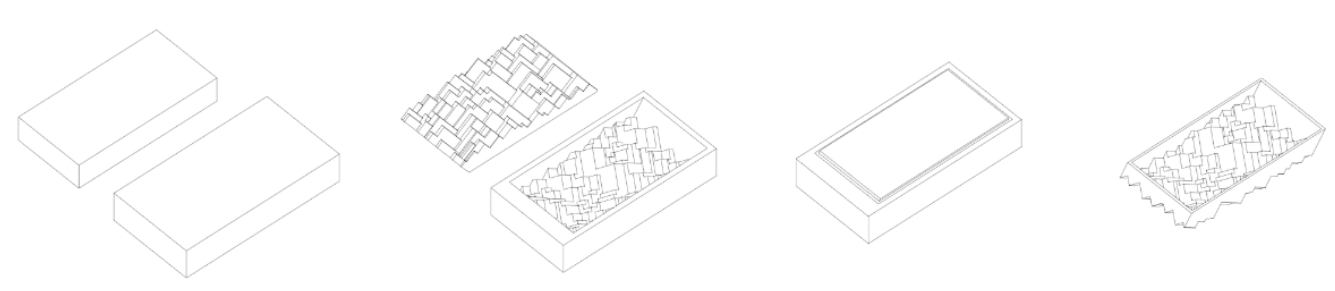

Figure 5 - Schemes of the ice feedstock volume, mould assembly and the end concrete product.

\section{Analysing Data on Energy Consumption of Refrigerated Container}

The power consumption of the refrigerated production unit was monitored during the nine months of the experiment and is represented in Figure 6 and Table 1. The black oscillating line is the outdoor air temperature and the orange line is an averaged power rate during a specific time period (SMHI 2020). The blue marks identify six reference periods of refrigerator idle mode. This data helped to identify the relation between outdoor air temperature and the rate of power consumption. The purple marks denote the production periods of the two prototypes.

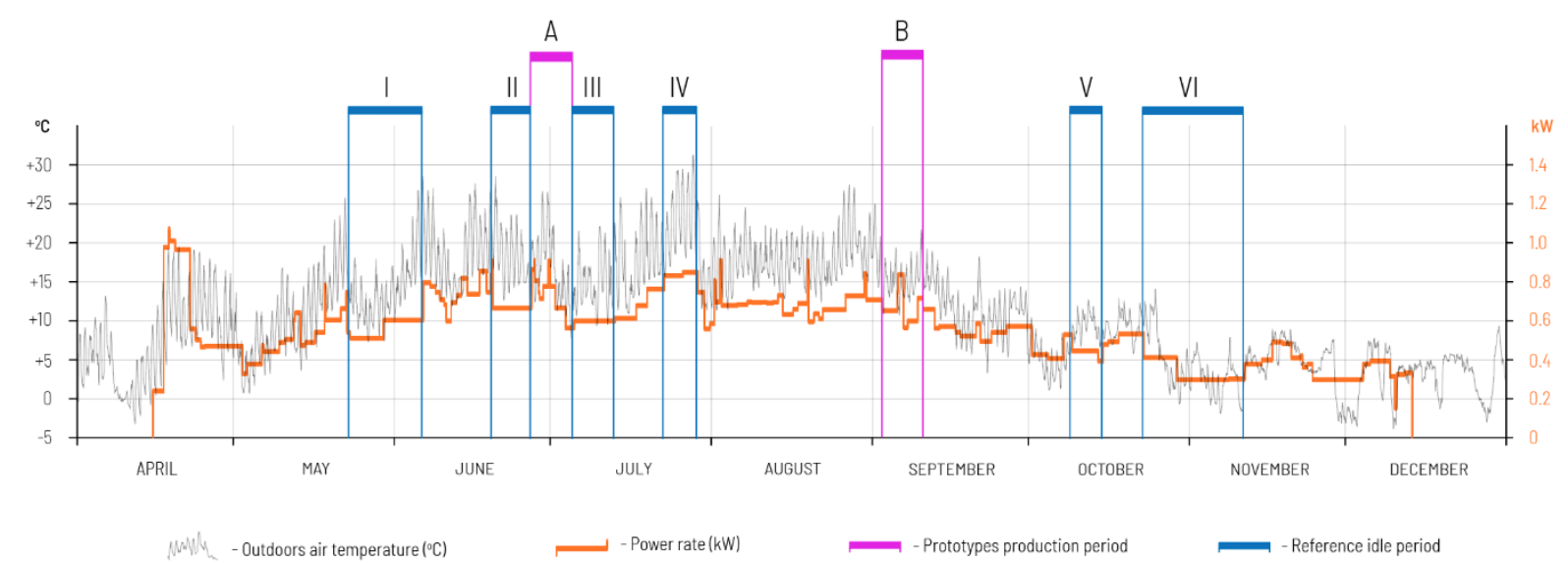

Figure 6 - Representation of the collected energy consumption data and notation of the analysed periods. 
Table 1 - Observed and calculated energy consumption

\begin{tabular}{|c|c|c|c|c|c|c|c|c|c|}
\hline \multicolumn{8}{|c|}{ Collected Data } & \multicolumn{2}{|c|}{ Equation 1 Calculations } \\
\hline \multirow{2}{*}{\multicolumn{3}{|c|}{ Specific Period }} & \multirow{2}{*}{ Hours } & \multicolumn{2}{|c|}{ Ambient Temperature } & \multirow{2}{*}{ kWh } & \multirow{2}{*}{$\mathrm{kWh} / \mathrm{d}$} & \multirow{2}{*}{$\begin{array}{l}\text { Est. EC } \\
\mathrm{kWh} / \mathrm{d}\end{array}$} & \multirow{2}{*}{$\begin{array}{c}\text { Offset } \\
k W h / d\end{array}$} \\
\hline & & & & K & C & & & & \\
\hline \multirow{6}{*}{$\begin{array}{c}\text { Reference } \\
\text { Idle Energy } \\
\text { Consumption }\end{array}$} & ref. I & $22 / 5-6 / 6$ & 353 & 287.3 & 14.1 & 184 & 12.5 & 12.3 & 0.2 \\
\hline & ref. II & $19 / 6-27 / 6$ & 181 & 291.4 & 18.3 & 116 & 15.4 & 15.5 & -0.2 \\
\hline & ref. III & $5 / 7-13 / 7$ & 190 & 288.2 & 15.1 & 107 & 13.5 & 13.0 & 0.5 \\
\hline & ref. IV & $22 / 7-26 / 7$ & 87 & 295.7 & 22.5 & 75 & 20.7 & 19.8 & 0.9 \\
\hline & ref. v & $9 / 10-18 / 10$ & 216 & 282.3 & 9.1 & 88 & 9.8 & 9.3 & 0.5 \\
\hline & ref. VI & $23 / 10-8 / 11$ & 391 & 277.4 & 4.2 & 117 & 7.2 & 7.1 & 0.1 \\
\hline
\end{tabular}

\begin{tabular}{|c|c|c|c|c|c|c|c|c|c|}
\hline Prototype & A & $27 / 6-8 / 7$ & 156 & 287.9 & 14.7 & 96 & 14.8 & $\mathbf{1 2 . 7}$ & $\mathbf{2 . 0}$ \\
\cline { 2 - 19 } Production & B & $5 / 9-17 / 9$ & 293 & 287.5 & 14.4 & 177 & 14.5 & $\mathbf{2 . 0} .5$ \\
\hline
\end{tabular}

Using the values of the periods of idle mode from Table 1, the relation between the outdoor temperature $\mathrm{x}$ expressed in Kelvin and the energy consumption per day $(\mathrm{kWh} / \mathrm{d})$ can been expressed with the following logarithmic function:

$$
f(x)=1 E-06 e^{0.0562 x}
$$

This function allows the rough estimate of energy consumption for outdoor air temperature values between $+4.2^{\circ} \mathrm{C}$ and $+22.5^{\circ} \mathrm{C}$. The difference between the idle and the operating rates of energy consumption was considered the 'Offset' of energy consumption, which identifies the additional energy spent on processing of ice and concrete in the refrigerated space.

For the average outdoors temperature of the periods $\mathrm{A}$ and $\mathrm{B}$ (the periods of two prototypes production), the calculated energy consumption was approx. $2 \mathrm{kWh} /$ day lower than the observed one. Considering that the mass of processed material in both cases was around $100 \mathrm{~kg}$ (including masses of ice and concrete), it can be said that the production caused a $16 \%$ increase in energy consumption. At the same time, a rise in the average outdoors temperature by $10^{\circ} \mathrm{C}\left(\right.$ from $+10^{\circ} \mathrm{C}$ to $\left.+20^{\circ} \mathrm{C}\right)$ doubles the energy consumption.

While these observations provide a preliminary idea of energy consumption rates of industrial refrigeration, they are not sufficient for extrapolation of the dependencies on a larger production volume. Development of a functional simulation for a wider range of parameters can be very useful for further argumentation.

\section{Analysing Production-Added Embodied Energy of Concrete Prototypes}

Apart from the values of the energy consumption discussed above, the data on production of the two prototypes allows a rough correlation between energy use and productivity to be established. As mentioned in Table 1, the production of prototypes A and B required 96 and $177 \mathrm{kWh}$, respectively. This can be considered as the production-added embodied energy of the concrete prototypes, which has to be added to the embodied energy of the concrete raw materials. Table 2 features these values along with an example of the energy intensity of a conventional production method based on EPS (row 'Expanded Polystyrene'). The embodied energy of concrete and EPS were estimated based on the Inventory of Embodied Energy and Carbon Footprint (Hammond and Jones 2011). 
Table 2 - Comparison of the concrete embodied energy and the production-added embodied energy.

\begin{tabular}{|c|c|c|c|c|c|c|c|c|c|c|}
\hline & \multirow[b]{2}{*}{ Prototypes } & \multicolumn{2}{|c|}{ Concrete Product } & \multicolumn{5}{|c|}{ Mould Production } & \multicolumn{2}{|c|}{ Added Embodied Energy } \\
\hline & & $\begin{array}{c}\text { Concrete } \\
\text { volume }\left(\mathrm{m}^{3}\right)\end{array}$ & $\begin{array}{l}\text { Concrete } \\
\text { mass } \\
(\mathrm{kg})\end{array}$ & $\begin{array}{c}\text { Mould/ } \\
\text { Concrete } \\
\text { volume ratio }\end{array}$ & $\begin{array}{l}\text { Feedstock } \\
\text { volume } \\
\left(\mathrm{m}^{3}\right)\end{array}$ & $\begin{array}{l}\text { Material } \\
\text { density } \\
\left(\mathrm{kg} / \mathrm{m}^{3}\right)\end{array}$ & $\begin{array}{l}\text { Material } \\
\text { mass } \\
(\mathrm{kg})\end{array}$ & $\begin{array}{c}\text { Refrigerated } \\
\text { process } \\
\text { (hours) }\end{array}$ & $\mathrm{kWh}$ & MJ \\
\hline \multirow{2}{*}{ Concrete } & A & 0.023 & 53 & - & - & - & - & - & 23 & 82 \\
\hline & B & 0.012 & 28 & - & - & - & - & - & 12 & 43 \\
\hline \multirow{2}{*}{$\begin{array}{l}\text { Expanded } \\
\text { Polystyrene }\end{array}$} & A & - & - & 2.1 & 0.048 & \multirow{2}{*}{30} & 1.4 & - & 36 & 128 \\
\hline & B & - & - & 8.3 & 0.100 & & 3.0 & - & 74 & 265 \\
\hline \multirow{2}{*}{$\begin{array}{l}\text { Ice Formwork } \\
\text { (actual) }\end{array}$} & A & - & - & 2.1 & 0.048 & \multirow{2}{*}{917} & 44.3 & 156 & 96 & 346 \\
\hline & B & - & - & 8.3 & 0.100 & & 91.3 & 293 & 177 & 637 \\
\hline \multirow{2}{*}{$\begin{array}{l}\text { Ice Formwork } \\
\text { (required) }\end{array}$} & A & - & - & 2.1 & 0.048 & \multirow{2}{*}{917} & 44.3 & 48 & 30 & 106 \\
\hline & B & - & - & 8.3 & 0.100 & & 91.3 & 48 & 29 & 104 \\
\hline
\end{tabular}

Based on the numbers provided in Table 2, it can be concluded that in all the production cases, the embodied energy of the mould exceeds the embodied energy of the moulded concrete raw materials many times. Also, it can be said that at this production scale, the use of EPS moulds requires less energy than the Ice Formwork method. Yet, in the case of the Ice Formwork production, the energy gradually accumulates during the whole production period, as the refrigerator energy consumption is roughly the same during the idle periods. In this respect, Table 2 also mentions a desired ice formwork energy performance, which can be achieved by reduction of the refrigerated production time to 48 hours. This calculation assumed that same energy consumption rate per day of refrigeration would occur if the ice processing speed were to increase, and the idle time were completely omitted. According to this logic, the row 'Ice Formwork (required)' shows that use of refrigeration can potentially be more energy efficient than the production based on EPS.

\subsection{Chemical Leaching from Concrete to Melt Water}

The second problem related to the ecological performance of the Ice Formwork production is the large amount of water involved in the process. While there is a clear economic and ecological advantage of continuous reuse of the same water in the production cycles, the problem of chemical leaching from premature concrete to melt water needs to be studied in further detail.

In practice, the contact of matured concrete with water poses practically no environmental concerns, and causes a very insignificant transfer of minerals from concrete to the contact water. However, if water comes in contact with fresh or premature concrete, the effect on water mineral content may be very strong, even to the extent that it becomes unsafe for release back into the natural environment. The Ice Formwork production method includes a stage in which a premature concrete element is demoulded by melting the ice mould. Due to a slower speed of hydration at a low temperature, it is impractical to wait until the concrete gains its total strength in the refrigerated environment. Thus, the concrete element would always be demoulded during the early stages of cement hydration, when the strength gain reaches approximately $20 \%$ of the total strength. Thus, the changes of the water mineral content after a production cycle should be examined. 

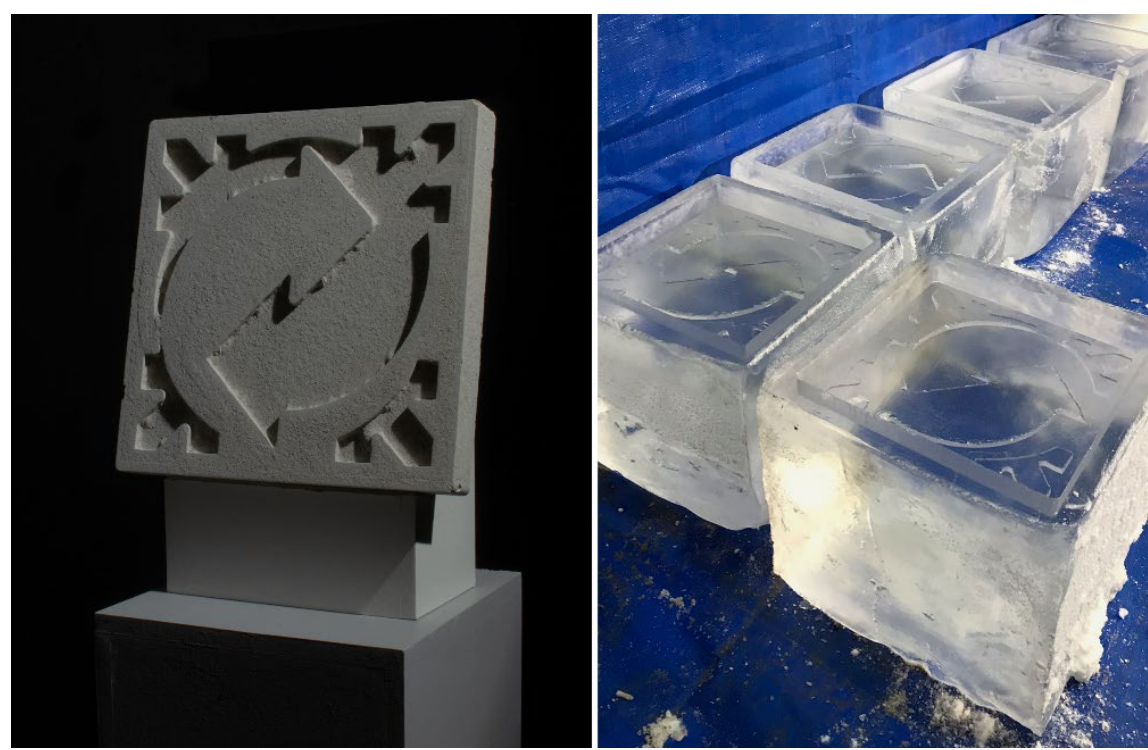

Figure 7 - Representation of the collected energy consumption data and the referential periods.

\section{Experimental Methodology of the Chemical Leaching Assessment}

In order to analyse the change of water mineral content during a production cycle, a subject-specific methodology has been developed. Five almost identical ice moulds have been made using the digital fabrication setup described earlier (Fig. 2). These moulds were filled with concrete in one batch, along with five sets of standard control beams (Fig. 7). All cast items were left to harden at $-10^{\circ} \mathrm{C}$. Each set was later thawed after 1, 3, 7, 14, and 28 days. The cast control beams were tested for compression and tensile strength on the day of thawing. The data on the state of concrete hydration is represented in Table 3.

Table 3 - Physical properties of the set of concrete samples produced for chemical leaching measurements

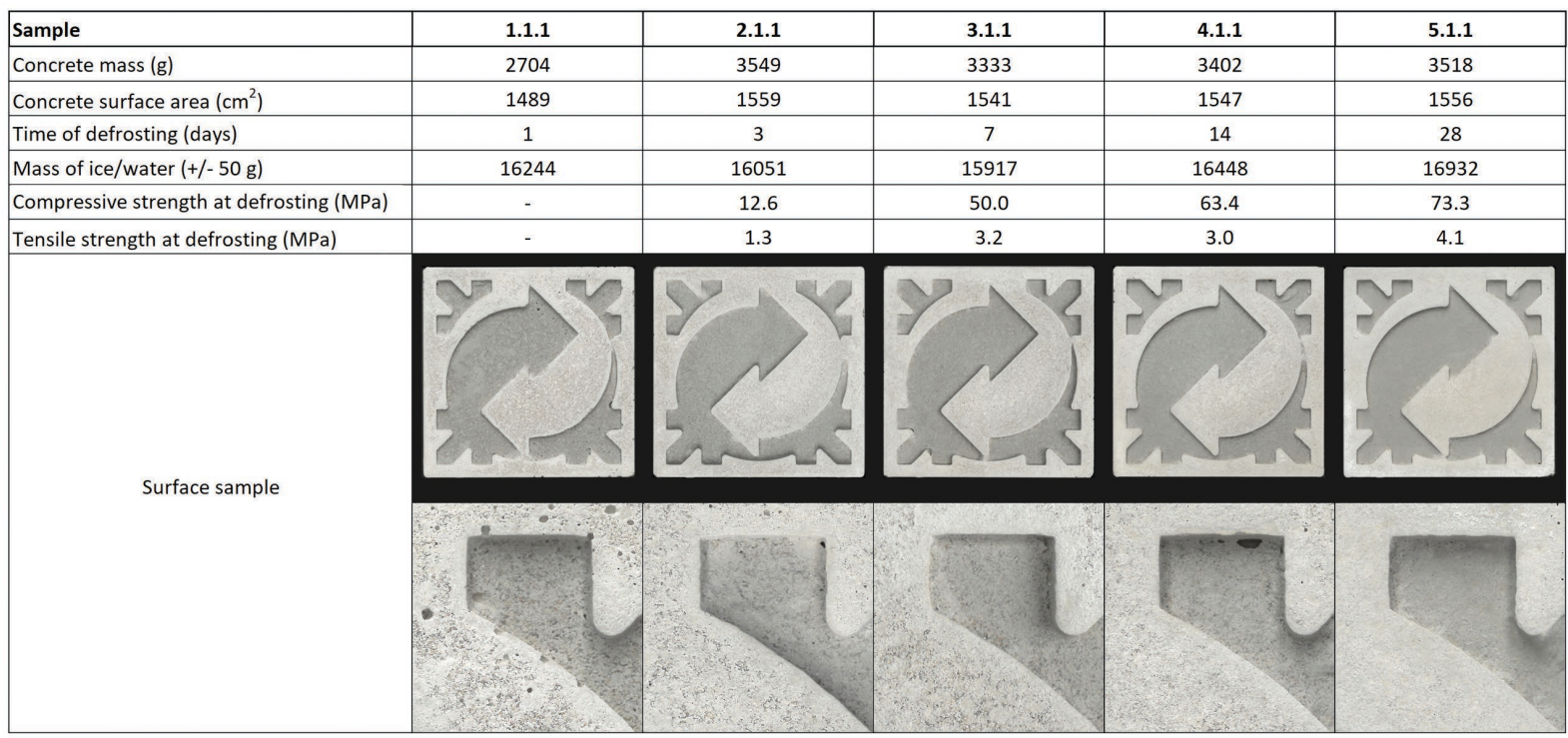




\section{Analysing the Chemical Leaching from Concrete to Melt Water}

The ice moulds were placed in watertight containers for the thawing process, thus melt water was in direct contact with the cast concrete samples. The water samples were taken after 48 hours, when all ice had been melted and had reached room temperature. Out of 22 minerals analysed in the water samples, five values showed a significant increase in concentration, namely: $\mathrm{pH}$, bicarbonate, and ions of chloride, calcium and sodium; see Fig 8 .

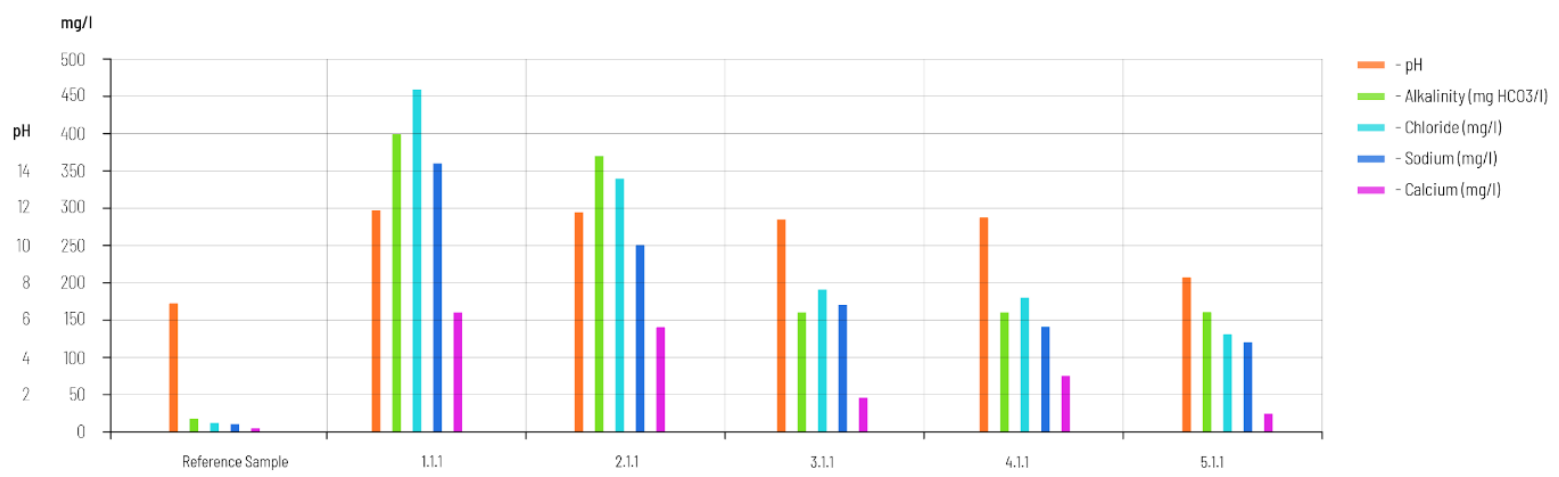

Figure 8-Chart of chemical leach from concrete to melt water depending on the level of cement hydration.

The $\mathrm{pH}$ of all ice moulds in contact with the young concrete increased significantly up to 14 days of cold concrete hydration (1.1.1-4.1.1), see the orange bars. After 28 , days the $\mathrm{pH}$ is only slightly elevated to $\mathrm{pH} 8$. The pore structure of the cement paste matures continuously though, and as a result, fewer ions diffuse into the ice mould/melt water, hence the reduction in concentration of these ions from 1.1.1 to 5.1.1. The chloride ion concentration reduces from ca $450 \mathrm{mg} / \mathrm{l}$ to ca $130 \mathrm{mg} / \mathrm{l}$. For comparison, the 'Reference Sample' featured in Figure 8 represents the mineral content of ice collected from the Torne River in northern Sweden. On the other hand, average Atlantic water contains ca $35000 \mathrm{mg} / \mathrm{l}$ dissolved salts (mostly chloride and sodium). In this respect, it can be assumed that the mineral content of the process water lies within the domain that can be encountered in nature.

However, reuse of this mineral-saturated process water and its associated drop in freezing temperature may increase energy consumption. A maximum dissolved salts level is expected where the concentrations of salts in the concrete and the ice formwork are isotonic; this has not yet been verified however. Alternatively, the water can be treated within the production facility, removing the ions and salts from the content using reverse osmosis, yet the energy intensity of this treatment needs to be calculated and juxtaposed with the increased energy consumption of refrigeration.

\section{Conclusion}

While the estimation of energy consumption by the Ice Formwork system presented in the work is very approximate, it provides a general image of a relatively unexplored field of climate-controlled production and showcases methodology for further large-scale testing.

Although the performed experimental work and data collection shows that the Ice Formwork production method requires significant amounts of energy for refrigeration, it can still become a favourable choice in comparison to EPS moulds due to the absence of material waste. The method should show a better performance, i.e. reduced energy consumption, in regions where the mean annual temperature is low. And since practical implementation of 
12

the production would push for ever shorter lead times, the energy invested in refrigeration would constantly tend to decrease in relation to productivity.

After the chemical assessment of the melt water, it remains true that the technology provides a sustainable material choice for moulding in production of prefabricated concrete elements. The $\mathrm{pH}$ of the melt water would need to be reduced before release if short production times are required though. After 28 days, the $\mathrm{pH}$ is significantly reduced from $\mathrm{pH} 11$ to $\mathrm{pH} 8$.

However, it is important to acknowledge that at the first place, the Ice Formwork production method is an efficient solution for the manufacturing of bespoke - e.g. non-repetitive - concrete elements, which are now gaining momentum in architectural and structural design due to the development of algorithmic design tools. It is reasonable to expect a substantial rise in the demand for these types of concrete products in the coming decades, and thus it is a good idea for the industry to prepare sustainable solutions for meeting this upcoming production challenge.

\section{Bibliography}

Diller Scofidio + Renfro. 2015. The Broad. https://dsrny.com/project/the-broad.

Ecoinvent. 2020. “Ecoinvent 3.6.” 2020. https://www.ecoinvent.org/database/ecoinvent-36/ecoinvent-36.html.

Flatt, Robert J., Nicolas Roussel, and Christopher R. Cheeseman. 2012. "Concrete: An Eco Material That Needs to Be Improved." Journal of the European Ceramic Society, Special Issue: ECerS XII, 12th Conference of the European Ceramic Society, 32 (11): 2787-98. https://doi.org/10.1016/j.jeurceramsoc.2011.11.012.

Gannon, Kevin. 2018. "Ultra-High Performance Concrete Panels and Prefabricated Wall Assemblies.” https://www.taktl1lc.com/taktltechnical-documents/.

Gehry Partners. 2014. Fondation Louis Vuitton. https://www.archdaily.com/555694/fondation-louis-vuitton-gehry-partners/.

Hammond, G., and C. Jones. 2011. Embodied Carbon: The Inventory of Carbon And Energy (ICE). University of Bath \& BSRIA.

Jambeck, Jenna R., Roland Geyer, Chris Wilcox, Theodore R. Siegler, Miriam Perryman, Anthony Andrady, Ramani Narayan, and Kara Lavender Law. 2015. "Marine Pollution. Plastic Waste Inputs from Land into the Ocean." Science (New York, N.Y.) 347 (6223): 768-71. https://doi.org/10.1126/science.1260352.

López López, D, D Veenendaal, M Akbarzadeh, and P Block. 2014. "Prototype of an Ultra-Thin, Concrete Vaulted Floor System.” Proceedings of the IASS-SLTE 2014 Symposium. http://block.arch.ethz.ch/brg/publications/451.

Morphosis. 2020. Sejong M-Bridge. https://www.morphosis.com/architecture/271/.

Schipper, H. R., S. Grunewald, P. Eigenraam, P. Raghunath, and M. Kok. 2014. "Optimization of the Flexible Mould Process for the Production of Double-Curved Concrete Elements." CIC 2014: The 1st Concrete Innovation Conference, Oslo, Norway, 11-13 June 2014, 11-13 june 2014.

Sitnikov, Vasily. 2019. "Ice Formwork for High-Performance Concrete: A Model of Lean Production for Prefabricated Concrete Industry." Structures, Advanced Manufacturing and Materials for Innovative Structural Design, 18 (April): 109-16. https://doi.org/10.1016/j.istruc.2018.11.004.

Sitnikov, Vasily, Peter Eigenraam, Panagiotis Papanastasis, and Stephan Wassermann-Fry. 2019. "IceFormwork for Cast HPFRC Elements." In Ubiquity and Autonomy: Paper Proceedings of the 39th Annual Conference of the Association for Computer Aided Design in Architecture, 616-27. ACADIA.

Sitnikov, Vasily, and Ivan Sitnikov. 2018. "Kinetics of UHPC Strength Gain at Subfreezing Temeratures.” In ACI Technical Publication: Durability and Sustainability of Concrete Structures, SP-326:117.1-117.8. Moscow: American Concrete Institute. 
SMHI. 2020. "Sweden's Meteorological and Hydrological Institute (Sveriges Meteorologiska Och Hydrologiska Institut)." 2020. https://www.smhi.se/q/Stockholm/2673730. 